\title{
Deviations from the Expectable Environment in Early Childhood and Emerging Psychopathology
}

\author{
Kathryn L Humphreys ${ }^{1}$ and Charles $\mathrm{H}$ Zeanah ${ }^{\star, 1}$ \\ ${ }^{1}$ Department of Psychiatry and Behavioral Sciences, Tulane University School of Medicine, New Orleans, LA, USA
}

\begin{abstract}
Current frameworks for understanding the link between early adverse childhood experiences and later negative life outcomes, including psychopathology, focus on the mediating negative impact on brain and biological systems in the developing child resulting broadly from stress and trauma. Although this approach is useful, we argue that the framework could be functionally extended by distinguishing the effects of two different types of abnormal input, both deviations from the expectable environment in early childhood. Specifically, we review the consequences of inadequate input (eg, neglect/ deprivation) and harmful input (eg, abuse/trauma) on brain and biological development. We then review evidence on the differential links between each type of abnormal input to four selected domains of psychopathology (indiscriminate social behavior, posttraumatic stress disorder, attention-deficit/hyperactivity disorder, and conduct problems), and consider potential mechanisms for inadequate and harmful input to lead to these outcomes. We conclude that the careful consideration of the type of deviation from the expected environment, while acknowledging the practical difficulties in assessing this, is likely to lead to clearer understanding of the mechanism of risk for psychopathology, and that tailored approaches to prevention and intervention may be informed by considering the unique consequences of inadequate and harmful input when experienced in early childhood.

Neuropsychopharmacology (2015) 40, I54-170; doi:I0.1038/npp.20I4.165; published online 6 August 2014
\end{abstract}

\section{INTRODUCTION}

Interdisciplinary perspectives are needed to understand how environmental factors have an outsized role in later-life outcomes in individuals and populations (Ben-Shlomo and Kuh, 2002; Halfon and Hochstein, 2002), with an understanding that early-life stressors predict a large degree of later-life outcomes (Hertzman and Wiens, 1996). Physiological responses to stress involve a cascade of cellular and molecular responses, which, over time, are thought to contribute to disease etiology (McEwen, 1998). Individuals are thought to differ because of innate genetic differences as well as by environmental supports and stressors (Boyce and Ellis, 2005).

The concept of 'toxic stress,' the cumulative and pernicious effect of multiple, chronic environmental adversities, is believed to disrupt developing brain circuitry and other organ systems, having long-term implications for physical and mental health (Shonkoff and Garner, 2012). A similar framework, organized around the adverse effects of young children's exposure to traumatic experiences, led to the

${ }^{*}$ Correspondence: Professor $\mathrm{CH}$ Zeanah, Psychiatry and Behavioral Sciences, Tulane University School of Medicine, 1440 Canal Street \#8055, New Orleans, LA 70112, USA, Tel: +1 504988 5402, Fax: +1 504988 4264, E-mail: czeanah@tulane.edu

Received 2 April 2014; revised 10 June 2014; accepted 28 June 2014; accepted article preview online 7 July 2014 creation of the National Child Traumatic Stress Network (NCTSN). The NCTSN was designed to enhance services for children who experience or witness traumatic eventswhich may consist of acute discrete events like a motor vehicle accident or chronic enduring circumstances like witnessing domestic violence or being abused. Repeated exposures to significant stressors have led some to propose 'complex trauma' as yet another framework used to examine the role of early adversity on later outcomes (van der Kolk, 2005). Considering the role of stress resulting from adverse experiences, especially early in development, these related frameworks share an emphasis on the negative events experienced by children, and how these events overwhelm their ability to cope adaptively. However, in order to provide further clarity into linking early adverse experiences and later outcomes, we propose in this paper to independently consider two types of deviation from expectable environmental input: (1) lack of necessary input, which we represent prototypically with studies of the effects of neglect/deprivation and (2) presence of harmful input, which we represent prototypically with studies of abuse/ trauma. Although there is debate regarding the definition of the range of environments considered within the 'expectable' range (see Baumrind, 1993; Scarr, 1992), both inadequate input and harmful input represent deviations from the expectable environment (a concept introduced by Nelson and colleagues to describe the effects of adversity at 
the neural level; Curtis et al, 2002; Fox et al, 2010; Nelson et al, 2014). Importantly, each type has been associated with a broad array of maladaptive outcomes, including various domains of psychopathology (National Research Council, 2013). By examining the two types of deviation separately, we aim to clarify the consequences of explicit stressors, a focus of most traditional approaches, as well as the consequences of neglect, on important developmental outcomes. The distinction between these two types of deviation from expectable environmental input may help guide both intervention efforts and policy in this area, and extends prior frameworks that focused more broadly on stress and trauma without specific regard to differential types of input from the environment.

Both the lack of necessary input and the presence of harmful input deviate from appropriate expectable caregiving experiences, especially in the crucial earliest years of life. Heightened plasticity of the brain in early life is a key feature of human development, and the infant brain relies upon environmental experiences in order to develop (Greenough et al, 1987). Two different processes were proposed by Greenough et al to understand how the environment informs brain development: experience expectant and experience dependent processes. Experience expectant processes involve information that nearly all members of the species will encounter (eg, language). Experience dependent processes involve unique information that is not experienced by all individuals (eg, one's native language). The impact of early experience on brain development has been said to 'cut both ways' (Hunt, 1979), given that the quality of the environmental input has a direct impact on the result of such plasticity, for better or worse. The heightened plasticity of the infant brain is in large part thought to reflect the nature of sensitive periods in development, that is, windows in which the brain is particularly open to adaptation by environmental input, which are typically clustered in early life (Knudsen, 2004). Although clearly delineated sensitive periods have yet to be defined in humans, the first 3 years is considered to be a vitally important time in the development of cognitive, affective, and social domains (Humphreys et al, in press). As humans are an altricial species, caregiver assistance is required for survival in infancy and childhood. However, the importance of caregivers extends beyond basic instrumental needs, as relationships with caregivers also provide an essential role in helping infants regulate their physical and emotional response to stressors (Tronick, 1989). Human infants are born with a strong propensity to form attachments to a small number of caregiving adults with whom they interact regularly and substantially in the earliest years of life (Bowlby, 2008). Developing attachments is experience expectant for human infants, although the quality of the attachments they develop depend upon the nature of their individual experiences with those caregivers and is therefore, experience dependent.

The failure of caregivers to provide co-regulation of children's emotional experiences has consequences for child development. Absent or neglectful caregivers fail to provide necessary interactive experiences that help the child develop skills ranging from language development (Hart and Risley, 1995) to social competence (Fantuzzo et al, 1998; Smyke et al, 2007). Caregiver-child relationships are internalized by the child, and the quality of the relationship may impact other contexts (Sroufe, 1983). In addition, given that emotionally available caregivers have a crucial part in helping children develop emotion regulation abilities (Field, 1994), children who experience deviations from the expectable environment in the form of neglect or abuse are at risk for a number of maladaptive outcomes that are compromised by ineffective emotion regulation (Kim and Cicchetti, 2010).

Frameworks used to study early-life stress typically emphasize the unidirectional effect of negative environmental experiences on child development and outcomes. However, considerable theoretical work has emphasized the transactional and dynamic interplay between individuals and their environment. The transactional model of development, first proposed by Sameroff and Chandler (1975), considers developmental outcomes, including psychopathology, as a function of ongoing transactions between the individual and the environment, which exert continual effects on one another. Similarly, relational developmental systems theory considers individuals as active and self-regulating, dynamically changing in response to and with the environment (Lerner and Overton, 2008). These frameworks emphasize the continuous dynamic a child has with the social context, which is considered essential for understanding developmental outcomes.

Thus, including the child in considerations of the impact of specific environmental inputs makes the deleterious effect of negative early experience even more evident, as environmental input elicits child behavior required for learning. For example, some experience expectant processes, including caregiver speech and language, are elicited and shaped in part by infants, and thus the absence of input from a caregiver results in an inability for the infant to obtain necessary experiences for adequate development. Although neglect/deprivation and trauma/abuse both involve the potential removal of expectable environmental experiences, the differing impact of these two forms of deviation (ie, inadequate $v s$ harmful input) may be seen in specific neurobiological and behavioral outcomes.

\section{Informative Longitudinal Studies}

Many of the studies of neglect/deprivation or trauma/abuse are cross-sectional, but longitudinal studies have proven valuable in tracing the emergence of psychopathology following maltreatment. In this review, we draw on three important longitudinal studies of early adverse caregiving. The first is a prospective cohort design study by Widom (1998) that included $>900$ children who were abused and/or neglected before the age of 12 years, identified from court records in a metropolitan area between 1967 and 1971. More than 600 children comprised the matched comparison 
group, selected from elementary school records, who had not been reported as maltreated but who were similar in other respects. Participants were interviewed at age 29 years about a number of domains of functioning, including psychopathology, substance use, educational attainment, employment, criminal history, and so on. The long-term follow-up and matched control group characteristics make the study uniquely informative.

The second study is the English and Romanian Adoptees Study, a longitudinal study of young children adopted from Romanian institutions for young children soon after the fall of Ceausescu (Rutter et al, 2010b). These children, mostly abandoned at birth, were placed in large institutions in conditions of material and especially social privation. The children were later adopted into English families, one group before 6 months of age, one group between 6 and 24 months, and a third between 24 and 42 months. The children have been evaluated comprehensively at $4,6,11$, and 15 years. The 'natural experiment' involving a sudden change from a deprived to an advantaged environment at different ages has yielded seminal insights into recovery following varying 'doses' of adversity.

Finally, the Bucharest Early Intervention Project (BEIP) is a randomized controlled trial (RCT) of foster care as an alternative to institutional care among 6- to 30-month-old children who were abandoned at birth and placed in Romanian institutions (Nelson et al, 2014; Zeanah et al, 2003). Half of the children were randomized to foster care and the other half to care as usual. The children were systematically assessed at 30,42 , and 54 months, at which time when the trial ended. The foster care network was handed over to government authorities when children were age 54 months. Follow-up assessments of the children at age 8 and 12 years have been completed. As a result of the RCT design, this study reduces selection bias that may be present in adoption studies, includes assessments of children while they lived in deprived conditions, and allows causal conclusions to be drawn about the effects of environmental enhancement.

\section{Aims}

These three studies, along with research conducted by many other groups, help to provide insight into the potential differing impact of deviations from the expectable environment on later psychopathology. In the present review, we begin with a brief overview of the impact of both inadequate input and harmful input on the developing brain. We then focus on four selected domains of psychopathology: indiscriminate social behavior, posttraumatic stress disorder (PTSD), attention-deficit/hyperactivity disorder (ADHD), and conduct problems, each linked to child maltreatment (National Research Council, 2013). We review evidence of the association of inadequate input and harmful input on each domain and explore the potential causal mechanisms for the increased risk for each type of psychopathology. Finally, we outline areas for future research to examine deviations from the expectable environment in the prediction of psychopathology from this two-pronged framework.

However, as an initial caveat, although our aim is to consider these two types of deviations, the effort is challenged by a number of issues. First, we cannot experimentally control human environments. Second, these two types of deviations from the expectable environment-lack of input and harmful input-often co-occur (Mennen et al, 2010). Third, we are unable to fully consider developmental differences, that is, effects based on when in the early years deviant experiences occur. This remains an important area for further inquiry for the identification of sensitive periods (Fox et al, 2010). Fourth, the difficulties in accurately assessing the onset, duration, and severity of negative environmental exposures in human populations, particularly in young children unable to report their experiences, each provide challenges to conducting research in this domain.

Nevertheless, we believe it is fruitful to explore the differing impact of the distinct effects of inadequate and harmful input on long-term outcomes, both mental and physical. We argue that the type of abnormal input experienced in early life may provide an important lens through which to further study deviations from the expectable environment and the developing child, and may bring us closer to identifying the mechanism by which early experiences result in differential brain and behavioral outcomes.

\section{IMPACT ON THE DEVELOPING BRAIN}

The human brain has a prolonged development compared with other species (Neubauer and Hublin, 2012), with deviations from the expectable environment during infancy and early childhood having profound effects. Greater plasticity during early life confers both advantages and disadvantages, but it underscores the importance of early experiences, either lack of input or harmful input (see McLaughlin et al, 2014; Sheridan and McLaughlin, 2014). The bottom-up approach of brain development is thought to potentially result in irreversible patterns of neural development (Greenough et al, 1987), placing increased importance on the first years of life. In this section, we review research on the neural and physiological correlates of each form of deviation from the expectable environment.

\section{Inadequate Input}

Recent research has explored neurobiological effects of deprivation, mostly from studies of children raised in institutions (for more detailed reviews, see Nelson et al, 2011, 2014). Briefly, both the structure and function of the brain are altered in currently and formerly institutionalized children, at least for those who were raised in these settings for significant periods of early childhood beyond 6 months of age. The timing of exposure to and removal from deprivation appears to vary by the domain of later functioning examined, including attention, executive function, and stress responsivity (Bos et al, 2009; Brett et al, in press-a; Ghera et al, 2009; Gunnar et al, 2001). 
Consistent structural findings include reductions in both gray and white matter volumes in children who experienced institutional deprivation (Eluvathingal et al, 2006; Mehta et al, 2009; Sheridan et al, 2012), compatible with smaller head sizes in these children (Johnson et al, 2010; SonugaBarke et al, 2008). In addition, specific disruptions in connectivity between the amygdala and the prefrontal cortex (PFC) have been demonstrated in post-institutionalized children (Gee et al, 2013; Govindan et al, 2010). The effects of deprivation on subcortical structures are mixed, however. For example, imaging studies of children raised in institutions have found inconsistent effects on amygdala and hippocampal size (Mehta et al, 2009; Sheridan et al, 2012; Tottenham et al, 2010) relative to controls. One study has documented decreased cerebellar volume associated with poorer performance on memory and executive functioning tasks (Bauer et al, 2009).

Brain functioning abnormalities in children with histories of institutional rearing were first demonstrated in a small study using positron emission tomography. Chugani et al (2001) showed that 10 children who had been adopted out of Romanian institutions had reduced metabolic activity in the PFC and amygdala compared with adult controls and children with refractory epilepsy. Subsequent studies of brain functioning have involved electroencephalography (EEG) and imaging studies. Institutional rearing appears to result in reduced electrical activity in higher frequencies and increased electrical activities in lower frequencies (Marshall et al, 2004, 2008; Tarullo et al, 2011), but for children placed with families before 24 months, Vanderwert et al (2010) demonstrated normalization of brain functioning.

Finally, significant alterations in cortisol metabolism in children living in institutions (Carlson and Earls, 1997) and in children adopted out of institutions (Gunnar et al, 2000; Wismer Fries et al, 2008) have been demonstrated. In addition, children adopted out of institutions showed lower levels of oxytocin and vasopressin following interaction with their mothers compared with controls (Wismer Fries et al, 2005), indicating potential deficits in responses to social interaction.

Many of these findings should be considered preliminary and in need of replication, but they do point to neurobiological effects of deprivation on brain structure and function in young children. Gene $\times$ environment interactions are a promising area for examining individual differences in response to maltreatment. Recent work found that amygdala reactivity to emotional faces was predicted by the interaction of prior experiences of emotional neglect and variation in a genoset comprising polymorphisms from within the FKBP5 gene, a gene linked to hypothalamicpituitary-adrenal (HPA) axis activity (White et al, 2012). These findings build upon work finding gene $\times$ environment interactions in behavioral phenotypes following neglect (eg, Drury et al, 2010, 2012a). Following a body of work linking maternal care and epigenetic changes in nonhuman animals, deprivation has been linked to telomere shortening, a marker of cellular aging, in children who experienced institutional care (Drury et al, 2012b).

\section{Harmful Input}

There has been considerable interest in exploring the impact of abuse and trauma on the developing brain and biological response system (see De Bellis, 2001). Early-life stress, which has been used to characterize exposure to abuse and trauma, as well as social deprivation in the form of neglect or institutional care, has been linked to a cascade of physiological processes including HPA axis, inflammatory, and hormone response (McEwen and Seeman, 1999). However, to date it is unclear the degree to which each set of responses is related to the varying types of stresses on the system (ie, inadequate or harmful input), as studies typically consider both forms of early adverse experiences together.

The body's biological stress response is considered essential for survival, allocating resources to help individuals orient to and react to threat. Although responses to stressful situations function as part of an adaptive process to regulate responses, the impact of chronic stressors have been linked to a number of negative outcomes (Boyce and Ellis, 2005). Long-term exposure to traumatic stress is associated with poorer attention, executive functioning, and cognitive performance (Wilson et al, 2011). The body's stress response has been well documented elsewhere (Lupien et al, 2009), as the physiological stress response leads to the release of the glucocorticoid hormone, cortisol, which has a role in metabolism, immune function, and long-term global physiological response. Cortisol metabolism has been found to be altered in children who experienced abuse. For example, children who were physically or sexually abused in early childhood had smaller diurnal decreases in cortisol than neglected children, however, this was only found in abused children with high internalizing symptoms (Cicchetti and Rogosch, 2010). In addition, the duration of abuse experienced by children was found to positively correlate with urinary cortisol levels (De Bellis et al, 1999).

In terms of the brain, subcortical areas including the amygdala and hippocampus, as well as the PFC, are the most studied regions affected by the experience of trauma. Structural studies have mixed findings, as pediatric and adult samples differ. Although not observed in maltreated children, adults who experienced maltreatment in childhood had smaller hippocampal volume, indicating a possible sleeper effect of maltreatment in childhood (Woon and Hedges, 2008). However, there is evidence of differential brain volume in other brain regions in childhood. After controlling for total gray matter volume, children who experienced trauma had larger middle-inferior and ventral PFC volume than comparison youth (Richert et al, 2006). No white matter volume differences were found.

Epigenetic changes, including telomere length and DNA methylation, are promising areas of research for understanding the role of early traumatic experiences in biological changes. Exposure to violence has been associated with 
shorter telomere length (Shalev et al, 2012). Physical abuse also has been linked to changes in DNA methylation, as several sites in the glucocorticoid receptor gene showed increased methylation in youth who have been abused compared with non-abused children (Romens et al, in press).

\section{EFFECTS OF EARLY ADVERSITY ON SELECTED DOMAINS OF PSYCHOPATHOLOGY}

We selectively review four domains of psychopathology using the framework of inadequate or harmful deviation from the expectable environment: (1) indiscriminate social behavior, (2) PTSD, (3) ADHD, and (4) conduct problems. These four domains were selected for illustration based on available literature and relevance to the potential differing impact of neglect/deprivation and abuse/trauma.

\section{Indiscriminate Behavior}

Phenomenology of attachment disorders and indiscriminate behavior. Putative attachment disorders in young children have been described since the middle of the twentieth century (see Goldfarb, 1945; Spitz, 1945), but they have been studied systematically only in the past 15 years. Two major patterns of disordered behavior in young children have been described: (1) a pattern characterized by emotionally constricted and socially unresponsive behavior known as reactive attachment disorder (RAD), and (2) a pattern defined by lack of expected reticence about interacting with unfamiliar adults and violation of social boundaries known as disinhibited social engagement disorder (DSED). In this selective review, we will limit ourselves to studies of the indiscriminate social behavior of DSED because it is more common and has been better studied than RAD (see reviews in Bakermans-Kranenburg et al, 2011; Rutter et al, 2009; Zeanah and Gleason, in press).

Indiscriminate behavior, sometimes termed indiscriminate friendliness,' is characterized by young children who exhibit a pattern of a lack of reticence about engaging socially with unfamiliar adults, wandering away from caregivers in unfamiliar settings, and willingness to accompany strangers without hesitation. In preschool children, attention seeking behavior, overbright emotional displays, and violation of physical and verbal boundaries of others also may occur (Zeanah and Gleason, in press).

Indiscriminate behavior is rare in epidemiological studies (Egger et al, 2006; Gleason et al, 2011b), but it is one of the most common social abnormalities described in young children living in institutions (Zeanah et al, 2002, 2005) and in those adopted out of institutions (Bruce et al, 2009; Chisholm, 1998; Rutter et al, 2010a). In addition to children in institutions, indiscriminate behavior has been identified in maltreated children in foster care (Boris et al, 2004; Oosterman et al, 2007; Pears et al, 2010; Zeanah et al, 2004). Estimates of those with persistent signs of indiscriminate behavior following early, serious deprivation are in the range of $10-20 \%$ of children (Gleason et al, 2011a; Rutter et al, 2010a).

Association between inadequate input and indiscriminate behavior. Social neglect is considered central to indiscriminate behavior. A diagnostic criterion for a diagnosis of DSED from the Diagnostic and Statistical Manual of Mental Disorders (5th edn; DSM-5; American Psychiatric Association, 2013) requires 'insufficient care' as a causal explanation for the clinical symptoms. This is important because children with Williams syndrome, a microdeletion syndrome of the seventh chromosome, demonstrate high levels of indiscriminate behavior, despite having no histories of deprivation (Jones et al, 2000). Other than this genetic disorder, indiscriminate behavior in young children is almost always associated with a history of severe neglect.

More work is needed to distinguish children demonstrating high sociability from indiscriminate behavior. A recent study suggested that physical touching of unfamiliar adults during a laboratory paradigm in which the stranger makes overtures to the child may distinguish indiscriminate behavior from ordinary sociability more readily than verbal interaction (Lawler et al, 2014). In keeping with the link between social neglect and indiscriminate behavior, evidence is consistent that indiscriminate behavior is readily apparent in a minority of young children being raised in institutions (Smyke et al, 2002; Zeanah et al, 2005), adopted from institutions (Chisholm, 1998; O'Connor et al, 2003), and in maltreated children in foster care (Boris et al, 2004; Zeanah et al, 2004).

Association between harmful input and indiscriminate behavior. Abuse may co-occur with neglect in early childhood, but to date no evidence has demonstrated that physical or sexual abuse alone leads to indiscriminate behavior. LyonsRuth et al (2009) did find that indiscriminate behavior was present in infants reared in families if they had been neglected or if their mothers had had psychiatric hospitalizations. Less clear is whether the latter group may have also neglected their infants. In other words, it is unclear whether serious psychopathology in mothers contributes to young children's indiscriminate behavior, or if the absence or presence of specific behavior matters more. Attempting to understand how early adverse experiences may result in increased indiscriminate behavior leads us to consider potential mechanisms that may mediate the association.

Potential mechanisms for abnormal input to result in indiscriminate behavior. Little is known about how the absence of input or neglect leads specifically to indiscriminate behavior. Several studies have explored neurobiological abnormalities in young children with indiscriminate behavior. One question addressed by several investigators has been whether social disinhibition is a manifestation of difficulties with inhibitory control more generally, which also has been identified in children raised in institutions 
(Gleason et al, 2011a; Roy et al, 2004). As inhibitory control seems dependent upon ventral frontostriatal circuitry (Durston et al, 2002), investigators have used tasks such as the Stroop, $\mathrm{Go} / \mathrm{No}-\mathrm{Go}$, or Bear-Dragon to assess behaviors reflecting these circuits. Studies have demonstrated modest to moderate convergence between measures of inhibitory control and indiscriminate behavior (Bruce et al, 2009; Gleason et al, 2011a; Pears et al, 2010).

EEG abnormalities in children who experienced institutional deprivation include increases in relative power in lower frequency bands and decreased power in high-frequency bands (Marshall et al, 2004, 2008; Tarullo et al, 2011; Vanderwert et al, 2010) compared with typically developing children. Tarullo et al (2011) demonstrated that among post-institutionalized children, these EEG power abnormalities at 18 months predicted indiscriminate behavior and poorer inhibitory control at 36 months. They speculated that cortical hypoactivation from early deprivation may lead to both reduced EEG power and indiscriminate behavior.

Olsavsky et al (2013) used fMRI to demonstrate that children adopted from institutions showed reduced amygdala discrimination between mothers and strangers compared with children with no history of institutional rearing or adoption. Reductions in mother-stranger discriminations were moderately associated with indiscriminate behavior. Those children with more prolonged institutional rearing showed reduced amygdala discrimination and more indiscriminate behavior.

Although physical or sexual abuse has not been reported as a contributor to indiscriminate behavior - at least in the absence of neglect-preliminary evidence indicates that other forms of abnormal input may be implicated. For example, Lyons-Ruth et al (2009) found that mothers' disrupted emotional interactions with their infants-defined by behaviors that included affective communication errors (eg, giving contradictory cues, nonresponse or inappropriate response to clear infant cues), role confusion (eg, selfreferential or sexualized behavior), negative-intrusive behavior (eg, verbal negative remarks or physical intrusiveness), disorientation (eg, appearing frightened by infant or disoriented wandering), and withdrawal (eg, failing to greet infant or backing away from infant approach) mediated the relationship between caregiving adversity and indiscriminate behavior. These findings are preliminary but they raise questions about whether harmful rather than just insufficient input may lead to indiscriminate behavior.

\section{Posttraumatic Stress Disorder}

Phenomenology of PTSD symptoms. PTSD involves a cluster of signs and symptoms that appear following an individual's exposure to a traumatic event or series of events. Traumatic exposures include witnessing the death or threat of death of another, actual or threatened serious injury, or actual or threatened sexual violation to self or other. Following exposure, the individual re-experiences or relives the event episodically and intrusively, avoids reminders of the trauma, shows reduced positive emotional expression and increased negative emotional states, and exhibits signs of central nervous system hyperarousal (American Psychiatric Association, 2013). Systematic research has demonstrated that children as early as the first year of life may show evidence of these symptom clusters following exposure to traumatic events. Young children express symptoms from each cluster somewhat differently than older individuals, and the algorithm for determining diagnostic threshold is slightly different than for older individuals, but the clinical picture is actually more similar than different (Scheeringa et al, 2011).

Association between inadequate input and PTSD symptoms. Given that PTSD requires exposure to an overwhelmingly frightening and threatening experience, one may expect that neglect is not related to PTSD. Nevertheless, several studies have documented that neglect is associated with developing PTSD or posttraumatic symptomatology. For example, Widom (1999) reported that in 29-year-old adults who had experienced childhood maltreatment, there was no difference in risk for PTSD among those who had experienced sexual abuse (23\%), physical abuse (19\%), or neglect $(17 \%)$, but all were at greater risk than a nonmaltreated comparison group (10\%). In addition, Widom found lifetime risk for PTSD in those with a history of sexual abuse (38\%), physical abuse $(33 \%)$, or neglect $(31 \%)$ did not differ. In a national sample of in-home and out-of-home care, 8- to 14-year-old children referred for child welfare investigation were not different in the rates of posttraumatic symptoms among children who had experienced physical abuse (10\%), sexual abuse (13\%), and neglect (13\%) (Kolko et al, 2010).

There are several possibilities for understanding the link between neglect and PTSD. First, neglect may co-occur with physical abuse, witnessing partner violence, or other potentially frightening experiences. For example, in a review of PTSD and maltreatment, neglect was classified with witnessing partner violence (Kearney et al, 2010). In addition, some studies did not clarify how classifications of types of maltreatment were made, nor specify the source of data for classifying the type of maltreatment. In an attempt to provide objective assessments, many studies rely on court records to determine the type of maltreatment, but this can be problematic. For preverbal or barely verbal children, fractures pathognomonic for abuse (eg, spiral fractures of the humerus) or even abusive head trauma when there is no clear evidence of a perpetrator may be tried in juvenile court as 'lack of supervision,' a type of neglect. This event then appears in a database as neglect, although the child clearly experienced abuse. In addition, even in samples with welldefined risk for neglect in the form of social deprivation because of institutional rearing, peer traumatization may occur given low levels of adult supervision (Ellis et al, 2004). A second explanation for a statistical link between neglect and posttraumatic symptoms is that early childhood neglect may predispose the individual to internalizing disorders 
(Bolger and Patterson, 2001), which may then render the individual more susceptible to PTSD following exposure to a trauma. In the longitudinal study of effects of maltreatment by Widom (1999), for example, she reports a PTSD prevalence of $31 \%$ two decades following the individual's exposure to neglect.

Association between harmful input and PTSD symptoms. By definition, experiences of abuse-physical, sexual, or emotional-are considered traumatic. Beyond abuse, any experiences that activate and overwhelm fear circuitry are traumatic, such as motor vehicle accidents, natural disasters, war experiences, and so on. Yet, only about 25 to $30 \%$ of individuals exposed to a traumatic event develop PTSD, although many more develop subthreshold symptomatology (Kessler et al, 1995). Type, severity, and intentionality of the trauma may affect risk for PTSD, and those exposed to multiple traumas may develop more severe and/or different numbers of PTSD symptoms, as well as other related biopsychosocial impairments, than those exposed to single event traumas (Ford et al, 2006; Suliman et al, 2009; van der Kolk, 2003).

Vulnerability to posttraumatic symptomatology following trauma exposure has been studied primarily in adults and includes two broad types of variables. Those that lead to increased anxiety reactivity, and those that lead a decreased sense of control over trauma-related thoughts (Bomyea et al, 2012). A meta-analysis in children has shown low to medium effect sizes for gender, ethnicity, pre-trauma psychological problems, and parental psychological problems. Trauma severity-objectively determined-is most strongly associated with risk of developing PTSD (Trickey et al, 2012). In young children, traumas that threaten the caregiver are associated with more severe posttraumatic symptomatology (Scheeringa and Zeanah, 1995; Scheeringa et al, 2006).

Potential mechanisms for abnormal input to result in PTSD symptomatology. PTSD differs from most other forms of psychopathology given the requirement of a traumatic event, and PTSD is now included with RAD and DSED in the DSM-5 in the Trauma- and Stressor-Related Disorders, given the shared requirement for an environmental stressor to occur as a criterion for diagnosis (American Psychiatric Association, 2013). It is difficult to study the impact of trauma on development separately from the study of posttraumatic stress, as all children who develop PTSD have experienced at least one traumatic event, and the comparison groups used by most researchers are non-traumatized individuals. Given that only a portion of children exposed to trauma go on to develop PTSD, these studies may not be identifying the specific impact of trauma on the brain in those who do not develop PTSD.

Traumas result in an initial activation of two different stress response systems-the HPA axis that regulates cortisol and the adrenergic system activated by the locus ceruleus-which are both initially adaptive, but prolonged or excessive activation have a number of deleterious effects on physical and mental health, including posttraumatic symptomatology. Although PTSD is often studied using a binary framework, there is substantial evidence that posttraumatic stress reactions should be considered on a continuum and that symptoms considered pathological may represent more severe manifestations of the biological stress response system.

Multiple neurotransmitter systems, including the serotonergic, opioid, and dopaminergic systems, have each been linked to specific symptom clusters in PTSD (De Bellis and Zisk, 2014). Brain volume, particularly the PFC, appear to be different in individuals who experienced trauma in childhood and developed PTSD. Although no differences were found in amygdala or hippocampal volume in children with and without PTSD, smaller cerebral volumes among children with PTSD was found (De Bellis et al, 2001). At follow-up, when children were an average of 13 years, there was a trend level effect for larger hippocampal volume in children with PTSD. Smaller total brain volume were found in children with posttraumatic stress compared with nonmaltreated youth (Carrion et al, 2001). A similar study examined brain volume after matching for socioeconomic status and found that children with PTSD had smaller brain volume in a number of regions, including the PFC, but had larger frontal lobe cerebrospinal fluid volume than nonmaltreated youth (De Bellis et al, 2002). Younger age of the trauma, as well as longer duration of the abuse, have both been found to predict smaller brain volume in youths aged 4-17 years with PTSD. Research using diffusion tensor imaging indicates a link between PTSD from abuse and reduced fractional anisotropy in the anterior and posterior midbody of the corpus callosum, compared with demographically matched children without a history of abuse (Jackowski et al, 2008). Further, fractional anisotropy in the corpus callosum was negatively correlated with a measure of anxiety, indicating that reduced myelination as a result of trauma may mediate the association between traumaexposure and psychopathology. Brain function has been found to be altered as well, for example, as children exposed to domestic violence were found to have increased anterior insula and amygdala activity to angry but not sad faces (McCrory et al, 2011).

Alterations in attention to threat appears to be a likely pathway for the experience of abuse to result in PTSD symptomatology. Children who have been physically abused have a lower threshold to detect angry facial expression than children who were not abused (Pollak and Sinha, 2002), indicating a potential bias to threatening stimuli, presumably due to the salience of anger in the environment for abused children. This bias may be particularly true when viewing one's parent $v$ s a stranger (Shackman et al, 2007). In addition to increased detection of angry emotional expression, children who have been physically abused require greater resources to disengage from angry faces (Pollak and Tolley-Schell, 2003), and show greater accuracy at identifying angry facial expression targets during a Go/No-Go type task (Pollak et al, 2001). Event-related 
potential (ERP) data indicate differential P300 activity in abused children, such that smaller P300 amplitude was found when viewing angry target faces, but no difference was found in other emotional target faces (Pollak et al, 1997). These attentional biases appear to indicate that abused children are vigilant to threat in the environment, a key symptom of PTSD, although the bias may be more specific to social than physical threats. For example, children with PTSD showed attentional biases specific to social-threat words and not to physical-threat words compared with nonabused youth (Dalgleish et al, 2001).

\section{Attention-Deficit/Hyperactivity Disorder}

Phenomenology of ADHD symptoms. ADHD is a neurodevelopmental disorder that typically presents in childhood, and comprises inattention, impulsivity, and disorganization and/or hyperactivity (American Psychiatric Association, 2013). The worldwide prevalence of ADHD is estimated at $5 \%$ (Polanczyk et al, 2007). Although often conceptualized and examined from a binary (ADHD vs no ADHD) or subtype (inattentive type, hyperactive/impulsive type, and combined type) approach, large-scale studies support that $\mathrm{ADHD}$ is better understood via a dimensional approach, with individuals arrayed on two continua of inattention and hyperactivity/impulsivity (Marcus and Barry, 2011). Etiologically, twin studies have supported high levels of heritability (Levy et al, 1997) for ADHD, indicating a strong genetic basis for the disorder. Along these lines, the DSM-5 states: 'Family interaction patterns in early childhood are unlikely to cause ADHD but may influence its course or contribute to secondary development of conduct problems' (American Psychiatric Association, 2013, p. 62). However, contrary to this emphasis on the genetic origins of $\mathrm{ADHD}$, several studies have linked early experiences to this phenotype.

$\mathrm{ADHD}$ is found at significantly higher rates among youth who have been the subject of a child welfare agency investigation, for example, with nearly $19 \%$ of these youth aged 12-17 years meeting criteria for ADHD, compared with a prevalence rate of $5 \%$ in the general population (Heneghan et al, 2013). Also, the type of symptoms associated with maltreatment may be specific to inattention and impulsivity, as a sample of school age children who experienced abuse or neglect had more severe levels of inattention and impulsivity, but not hyperactivity, compared with nonmaltreated children (Becker-Blease and Freyd, 2008). Although research linking specific forms of early experience to ADHD is relatively new, we next review specific studies by type of input (ie, inadequate or harmful).

Association between inadequate input and ADHD symptoms. Briscoe-Smith and Hinshaw (2006) examined history of abuse and neglect in 228 girls aged 6-12 years with and without ADHD. Girls with ADHD were significantly more likely to have been neglected than their non-ADHD counterparts. The type of neglect may differentially impact
ADHD symptom domains, as research from the National Longitudinal Study of Adolescent Health (AddHealth) indicated that supervision neglect (placing the child at risk for physical or psychological harm), predicted both the inattentive type $(\mathrm{OR}=1.6)$ and hyperactive type $(\mathrm{OR}=1.5)$, while physical neglect was a strong predictor of the inattentive type $(\mathrm{OR}=2.1)$ but was not significantly associated with hyperactive type (Ouyang et al, 2008).

Among children who experienced severe neglect in the form of institutional care during early childhood, signs of ADHD are highly prevalent, and these problems are often found in combination with other deprivation-specific mental health problems (eg, quasi-autism, disinhibited attachment, cognitive impairment) (Kreppner et al, 2007; Rutter et al, 2010a). Over one-quarter of Romanian children reared in orphanages aged 2-6 years fell above the screening cutoff on the ADHD inattentive scale from the Early Childhood Inventory-4 (Ellis et al, 2004). Increased rates of ADHD also were found in the BEIP. At age 54 months, children who had experienced institutionalization were significantly more likely to meet criteria for $\mathrm{ADHD}$ than never institutionalized comparison children $(21 \%$ vs $3 \%, \mathrm{OR}=7.4)$ (Zeanah et al, 2009). Consistent with conceptualizations that early experience impacts $\mathrm{ADHD}$, the length of the deprivation experience appears to be meaningful in the prediction of ADHD symptom severity. Several studies have examined age of adoption in relation to inattention in children who were institutionalized, although the specific cutoff ages varied by study. Using a cutoff of 24 months, Gunnar et al (2007) found that children adopted from institutional care before 24 months of age were somewhat more likely to have clinical levels of attention problems compared with noninstitutionalized youth (19\% vs $12 \%)$, and those who were adopted following 24 months of age were significantly more likely to have attention problems (42\%). In another study, the 24-month cutoff appeared less relevant, as children adopted from Romanian orphanages between the age of 6 and 24 months as well as after 24 months had higher levels of ADHD symptoms measured at age 6 years than children adopted from with the United Kingdom (Kreppner et al, 2001). However, among the Romanian adoptees, older age of placement into their adoptive home was linearly related to $\mathrm{ADHD}$ symptoms, indicating a dose-response effect for ADHD and deprivation experiences. In a third study that examined ADHD following exposure to varying amounts of institutional care, children adopted after 12 months of age had significantly higher levels of ADHD than both children adopted before 8 months of age and non-institutionalized comparisons (Wiik et al, 2011). These results are especially important in suggesting that postnatal experiences impact symptomatology.

Association between harmful input and ADHD symptoms. Levels of ADHD also appear to be elevated following experiences of abuse and trauma. Girls with ADHD were significantly more likely to have been sexually abused than their non-ADHD counterparts, although no increased evidence of 
experiences of physical abuse were found (Briscoe-Smith and Hinshaw, 2006). In a sample of children and adolescents with a range of psychopathology, the rates of trauma exposure were found to be highest in individuals with comorbid ADHD and oppositional defiant disorder (ODD), indicating a potential causal role in the association between trauma and disruptive behavior disorders (Ford et al, 2000). However, other studies indicate no differences in trauma exposure between children with and without ADHD (Wozniak et al, 1999), although notably the age in which trauma exposure was measured was not isolated to early life. Data from the AddHealth study indicate that both physical abuse and sexual abuse predicted ADHD inattention type $(\mathrm{OR}=1.6$ and 2.6, respectively), while only physical abuse was a significant predictor of hyperactive type $(\mathrm{OR}=1.3)$ (Ouyang et al, 2008).

Potential mechanisms for abnormal input to result in ADHD symptoms. Despite the general focus on the genetic basis in determining the etiology of ADHD, Conway et al (2011) proposed that ADHD symptomatology cannot be extricated from chronic early adverse experiences, especially given that disruptions in attachment relationships are found at significantly higher rates among children later diagnosed with ADHD. Recently, an etiologically based system for defining types of ADHD has been proposed, which includes both a largely genetically driven type of ADHD as well as a 'phenocopy' of ADHD that results from early negative childhood experiences (Webb, 2013). This system implies that the pattern of attention, hyperactivity, and impulsivity related concerns are similar despite the differing causal elements. However, some have questioned whether attentional difficulties among children who experienced institutional rearing are the same as those experienced by noninstitutionalized youth. For example, Loman et al (2013) found that behavior on a Go/No-Go task was more reflective of overall sustained attention deficits among previously institutionalized youth, rather than specifically related to executive attention.

The potential mechanism in the association between experiences of severe neglect and ADHD are not well understood. However, research from the BEIP identified EEG patterns that mediated the association between institutionalization and ADHD symptoms (McLaughlin et al, 2010), which is consistent with evidence of EEG differences in those with ADHD from non-institutionalized samples (Snyder and Hall, 2006). McLaughlin et al found that reduced alpha relative power and increased theta relative power predicted symptoms of hyperactivity and impulsivity in institutionalized children at age 54 months. Importantly, the effect of EEG power appeared specific to ADHD symptoms, as there was no association between EEG power and either internalizing symptoms or disruptive behavior symptoms. Additional evidence that neural activity differences following deprivation are associated with attention problems comes from ERP to facial stimuli. Peak amplitude of the P700 to faces mediated the association between exposure to institutional care and symptoms of ADHD at age 54 months (Slopen et al, 2012).

Institutional rearing leads to prevalence rates of ADHD of around 20\% (Rutter et al, 2010a; Zeanah et al, 2009), which is four times greater than the worldwide prevalence figure. As most of the children in these studies were abandoned and placed in institutions at or near birth, it is unlikely that selective placement can account for the increased prevalence rates. Using structural imaging, recent data from BEIP (McLaughlin et al, 2013) demonstrated that 8-year-old children with ADHD and histories of institutional rearing had widespread cortical thinning similar to what has been described in children with ADHD without histories of deprivation (Narr et al, 2009; Shaw et al, 2006). Specifically, investigators demonstrated that Romanian children reared in institutions had higher levels of ADHD symptoms and exhibited widespread reductions in cortical thickness across prefrontal, parietal, and temporal regions compared with never institutionalized Romanian children. Further, cortical thickness in the middle frontal gyrus, orbitofrontal cortex, supramarginal gyrus, and inferior parietal cortex significantly mediated the association between institutional rearing and inattention, and thickness in the middle frontal gyrus, orbitofrontal cortex, and superior temporal gyrus mediated the association with impulsivity. Cortical thinning explained $20 \%$ of the association between institutionalization and inattention and $27 \%$ of the association between institutionalization and impulsivity. This means that similar brain changes have been demonstrated in ADHD known to be highly heritable and in ADHD arising in conditions of severe deprivation. The latter group is important since most of the children raised in institutions were abandoned at birth.

Other forms of deprivation-specific psychopathology may also have a role in the development of ADHD symptomatology, as indiscriminate social behavior at age 18 months predicted ADHD symptoms, including hyperactivity at age 5 years (Lyons-Ruth et al, 2009). Also, in the ERA study, there was an association between indiscriminate behavior and inattention/overactivity (Stevens et al, 2008).

In terms of the potential link between harmful input and $\mathrm{ADHD}$, there is evidence that intrusive caregiving measured at age 6 months predicted hyperactivity in early and middle childhood (Carlson et al, 1995). Although parenting behaviors may elicit ADHD-type behaviors, the possibility of 'child effects' also merits consideration in our understanding of directionality for ADHD in older children. Attention problems at age 12 years predicted mother-child rejection assessed at a 1-year follow-up, even after controlling for initial mother-child rejection (Lifford et al, 2008). Children with ADHD may be more likely to elicit negative or harsh parenting, as parents with children with ADHD are significantly more likely to use corporal punishment compared with parents of children without ADHD (Alizadeh et al, 2007), thus, risk for abuse may be higher among children with ADHD. It is likely that the experience of trauma results in ADHD symptomatology. In a study of 
young adults, the experience of physical or sexual abuse during childhood (before age 17) was associated with higher levels of ADHD symptoms (Singer et al, 2012). Importantly, although not confined to abuse during young childhood, the study identified individual differences in coping selfefficacy as a potential mediator of the association between child abuse and ADHD, suggesting that the attention problems experienced following abuse may be related to poorer coping.

Further support for the environmental role in ADHD comes from data suggesting that enhancing positive caregiving reduces ADHD symptoms. Mother-child dyadic intervention has been found to result in decreased ADHD symptoms in young behaviorally disordered children (Boggs et al, 2005). In another intervention, two types of foster care placements following institutionalization were examined. Children placed in a high-quality foster care had significantly lower levels of ADHD compared with those in a government sponsored foster care, which had less support available for caregivers (Tibu et al, 2014). In addition to environmental factors, gene $\times$ environment interactions may provide a common link between genetic and environmental debates on the etiology on this phenotype. In a study examining maltreatment of participants from AddHealth, girls with the 10-10 repeat genotype within the dopamine transporter gene were significantly more likely to have problematic levels of ADHD following maltreatment than girls without this genotype (Li and Lee, 2012). Much work remains in isolating the specific roles of neglect and abuse/ trauma in the onset of ADHD, and whether these experiences may exacerbate potential genetic predispositions for attention problems or act as an independent risk factor in the presentation of this disorder. To date, evidence suggests that both types of deviation may result in ADHD symptomatology and through similar neural pathways, although this remains to be clarified, especially regarding similarities and differences in ADHD found in individuals with and without a history of adverse early experiences.

\section{Conduct Problems}

Phenomenology of conduct problems. Conduct problems include oppositionality, aggression, and rule violating behavior. This domain of behaviors has been examined both dimensionally and through categorical diagnoses of ODD, conduct disorder (CD), and antisocial personality disorder (ASPD), typically manifesting developmentally from the preschool years into adulthood. Recent work has emphasized the origins of conduct problems in early childhood (first 3-5 years), indicating that a subset of youth with conduct problems can be reliably identified as early as age 3 years, with modest to moderate stability in externalizing psychopathology from early childhood into adolescence (Shaw et al, 2012). Although ADHD is sometimes considered within the broader domain of externalizing psychopathology, there is support for the conceptual separation of ADHD and conduct problems (Achenbach, 1991; Frick and Nigg,
2012). Twin studies have provided evidence for moderate to high levels of heritability for conduct problems and related traits, such as callous-unemotional features (Viding et al, 2007), although environmental factors should be considered in the development of conduct problems.

Early negative experiences, including living in poverty and harsh and especially coercive parenting, are well-known risk factors for conduct problems. The experience of trauma, specifically, has been linked to conduct problems. In a retrospective study, children with ODD, both with and without comorbid ADHD, were found to have heightened rates of trauma exposure (Ford et al, 2000). In preschool children, $80 \%$ of those with PTSD had comorbid ODD, and nearly $80 \%$ of parents reported onset of ODD after the traumatic event (Scheeringa et al, 2003). In a long-term study of maltreated children, individuals who experienced abuse or neglect in the preschool years (age 3-5 years) were significantly more likely to meet criteria for ASPD in adulthood than children who experienced maltreatment only during infancy (Kaplow and Widom, 2007). Other findings support the association of maltreatment with conduct problems in adulthood, as nearly twice as many victims of abuse or neglect were found to have engaged in fighting than nonmaltreated youth (Stouthamer-Loeber et al, 2001).

Association between inadequate input and conduct problems. Neglect experienced during childhood has been associated with higher levels of conduct problem behavior (Thornberry et al, 2001). In a prospective longitudinal study of aggression, children who experienced neglect in the first 2 years of life demonstrated high levels of aggression toward peers at 4, 6, and 8 years (Kotch et al, 2008). However, in studies specific to extreme social deprivation in the form of orphanage rearing, findings are mixed. Data from the ERA study indicated no association between institutional care and conduct problems (Kreppner et al, 2001). Similarly, there was not a main effect of previous institutionalization on falling above the clinical threshold for externalizing problems (Gunnar et al, 2007). Yet, there was a significant effect of age of adoption, in which children adopted after age 24 months were significantly more likely to be above the clinical cutoff for both aggression and delinquent behavior than those adopted at an earlier age, indicating doseresponse effects may be relevant to the development of externalizing behavior. Increased conduct problems following institutional care has also been reported. For example, in one study nearly one-quarter of institutionally reared children aged 2-6 years fell above the screening cutoff for ODD (Ellis et al, 2004), and previously institutionalized 8- to 11-year-old children were found to have higher levels of externalizing symptoms (separate from ADHD) compared with never-institutionalized youth (Wiik et al, 2011).

However, externalizing psychopathology may emerge later in development following institutional rearing, reflecting a 'sleeper effect.' For example, institutionalized children did not differ from never institutionalized children in either 
ODD or CD diagnosis at 54 months in BEIP (Zeanah et al, 2009). However, by age 12 years, assessments from this same sample indicate both higher levels of ODD symptoms (Zeanah, 2014) and callous-unemotional traits (McGoron et al, 2013) among children who remained in institutional care.

Association between harmful input and conduct problems. The link between harmful input in the form of abuse or trauma with the development of conduct problems is more clearly supported by current research. The experience of abuse or exposure to interpersonal violence during childhood predicted higher levels of both ODD and CD symptoms (Boden et al, 2010). Children who experienced physical abuse before the age of 5 years were four times more likely to have conduct problems in 3rd and 4th grade compared with non-abused children (Dodge et al, 1995). Physically and sexually abused children were more likely to bully others than nonmaltreated youth (Shields and Cicchetti, 2001). These children also had higher scores on a composite index of disruptive behaviors. In a large cohort study of individuals followed for over four decades of childhood sexual abuse, the odds ratio for the development of CD was 6.32 (Cutajar et al, 2010). Another study found that while childhood sexual abuse predicted CD in early adulthood, the association between physical abuse and CD was only significant when sexual abuse was not considered within the model (Fergusson et al, 2008), indicating that sexual abuse may have a more direct relationship with later conduct problems.

Parenting behaviors have been linked to the onset and maintenance of children's aggressive and delinquent behaviors. Specifically, coercive parent-child interactions, characterized by inconsistent parental follow-through on commands and discipline reinforce negative child behavior. These types of coercive parent-child interactions are found in higher rates among abusive parents, indicating a potential confluence of harmful environmental inputs in these families (Patterson, 2002).

There may also be a dose-response relationship between abuse severity and conduct problems, as both emotional abuse and physical abuse in the early years has been linked to aggression and externalizing symptoms in school-age children, with greater abuse severity predicting increased symptoms (Manly et al, 2001). Similarly, the age in which the abuse occurred appears to impact later risk for conduct problems. Children who experienced physical abuse before the age of 5 years had significantly higher levels of externalizing compared with both children abused between the age of 6 to 9 years and children who were not abused (Keiley et al, 2001). Data from this same sample indicated that physical abuse before entry to Kindergarten predicted longterm negative outcomes, as parent-reported aggression and delinquency were approximately twice as high among children who have been abused compared with those who had not (Lansford et al, 2002). Still, very early abuse, occurring during the first 2 years of life was not associated with aggression toward peers from age 4 to 8 years (Kotch et al,
2008). Given the varying findings about age of exposure, and known developmental trajectories of brain development, potential mechanisms merit further examination.

Potential mechanisms for abnormal input to result in conduct problems. Environmental factors are thought to have a major role in the emergence of conduct problems. Children with multiple foster care placements had higher levels of oppositionality than those with stable placements and those never-placed in foster care (Lewis et al, 2007). Although it is likely that behaviorally difficult children are more likely to be moved, it is also likely that the disruptions of stable relationships caused by multiple placements result in increased aggressive or defiant behaviors. As such, stable placements in high-quality homes may reduce conduct problems. Yet, in contrast to findings that environmental interventions are the most effective treatment for conduct problems, quality of foster care environment was unrelated to externalizing disorder symptoms in the BEIP (Tibu et al, 2014). These findings may indicate that the deprivation pathway to externalizing could be less responsive to traditional treatments.

Although there is evidence of specific neural differences in youth with and without $\mathrm{CD}$, the environmental role in the onset and maintenance of these differences are unknown. Among youth with $\mathrm{CD}$, abnormal white matter connectivity between the amygdala and orbitofrontal cortex has been found (Passamonti et al, 2012). In addition, reduced gray matter amygdala volume was found in youth with CD compared with healthy comparison youth (Fairchild et al, 2011). The finding of reduced amygdala volume is counter to the enlarged amygdala volumes found in children with experiences of early deprivation (Tottenham et al, 2010). Similarly, reduced functional amygdala activity was found when children with conduct problems viewed emotional faces (Jones et al, 2009). Although the structural and functional findings associated with conduct problems appear to differ from changes resulting from abnormal early input, equifinality may explain the differential paths to $C D$ risk in different populations. Gene $\times$ environment interactions may also provide insight into how early abnormal input may interact with genetic predispositions in the development of conduct problems. In support of this, there is recent evidence from BEIP that the impact of deprivation on externalizing symptoms is moderated by genetic factors. Individuals with the 'susceptible' $s / s$ serotonin transporter genotype had heightened externalizing symptoms at 54 months of age compared with those without the $s / s$ genotype (Brett et al, in press-b). These findings suggest a potential role for differential susceptibility in the impact of early deprivation experiences on conduct problems. Similarly, gene $\times$ environment interactions have been found following physical abuse and later antisocial behavior, with a functional polymorphism in the monoamine oxidase A gene that appeared to increase vulnerability to antisocial behaviors among boys who were abused (Kim-Cohen et al, 2006).

The potential for disrupted HPA axis functioning as a mediator between maltreatment and conduct problems also 
has been considered. In one study, heightened morning cortisol and decline in cortisol across the day were associated with physical aggression, while low morning cortisol and relatively flat diurnal cortisol change were associated with relational aggression (Murray-Close et al, 2008). However, maltreatment moderated the effect as dysregulated cortisol patterns were found among the nonmaltreated youth but not the maltreated children. In other words, no association between externalizing and cortisol patterns among maltreated youth has been identified (Cicchetti and Rogosch, 2001; Dozier et al, 2006). Thus, further work is needed to clarify the differential biological profiles in potentially etiologically distinct pathways to conduct problems.

Emotion dysregulation is a potential mediator in the association between maltreatment and externalizing psychopathology (Shields and Cicchetti, 2001). Neglect, physical abuse, and sexual abuse all predict emotional dysregulation, which in turn predicted externalizing symptoms (Kim and Cicchetti, 2010), with a stronger association in children who experienced maltreatment during infancy or toddlerhood compared with those who experienced maltreatment in the preschool or school age period. Behaviors associated with emotional dysregulation lend support to this mediator, as children who experienced abuse or neglect did not differ from nonmaltreated youth in covert aggression, but had significantly higher levels of overt aggression (Stouthamer-Loeber et al, 2001), which is likely to be related to poorer emotional regulation.

Another potential pathway between early adverse experiences and conduct problems includes a developmental cascade from other forms of psychopathology. For example, LyonsRuth et al (2009) identified continuity in attachment problems as indiscriminate social behavior in early childhood predicted age 5 hostile behavior. In addition, as stated above, girls with a history of abuse or neglect were much more likely to be diagnosed with ADHD in middle childhood (Briscoe-Smith and Hinshaw, 2006), however, notably all of these girls diagnosed with ADHD following maltreatment also met criteria for ODD. In other words, compared with only half of the nonabused girls who had comorbid ADHD and ODD, all of the abused girls met criteria for both disorders. Consistent with these findings, parent and teacher rated externalizing problems, as well as peer and staff ratings on aggressive behavior, were higher among those girls with ADHD who had been abused. These findings indicate that externalizing psychopathology is more likely to present along with other domains of psychopathology. The delay between the early adverse experience and onset of symptoms requires careful assessment longitudinally, and the effect of prenatal exposure to substances (D'Onofrio et al, 2007), when available, should be included to examine the differential role of prenatal exposure to substances as an additional etiological pathway.

\section{FUTURE RESEARCH DIRECTIONS}

In this paper, we suggest that refining the measurement of adverse early experiences may prove to be a necessary step in illuminating how risks are translated into maladaptive behaviors. For example, the fact that social neglect and deprivation lead to increased risks for inattention and impulsivity, associated with widespread cortical thinning similar to what has been reported in the more heritable etiologically based ADHD found in non-neglected samples, elicits questions regarding the cellular and molecular processes involved in these pathways. Similarly, the fact that social neglect and deprivation lead to indiscriminate social behavior that is phenotypically similar to the indiscriminate behavior associated with microdeletions on the seventh chromosome begs similar questions about molecular pathways (Soares et al, 2013).

Although we have preliminarily considered the independent effects of both inadequate and harmful input, we recognize that these are often confounded in studies of adverse experiences. Over $50 \%$ of individuals from the ACE Study who reported childhood physical neglect also endorsed physical abuse during childhood, whereas approximately $20 \%$ of physically abused youth also reported physical neglect (Dong et al, 2004). And yet, at the level of circuitry, we speculate that the effects of inadequate input are distinguishable from the effects of harmful input, although each has effects on brain structure and functioning. Of course, many children experience both harmful and inadequate input, and as noted above, the lack of an attentive caregiver reduces both the potential for buffering stressful experiences and for fostering experience expectant developmental processes. Also, prenatal exposure to illicit substances may be a common, confounding factor, to consider in the outcomes of children who experienced either type of deviation from the expected environment. Among infants in a Russian institution, more than half displayed facial phenotypic signs of prenatal exposure to alcohol, which tended to be substantiated by maternal history when available (Miller et al, 2006). Prenatal exposure to alcohol was found to predict child maltreatment (composite of physical and sexual abuse and neglect) (Smith et al, 2007). Further, children who experience neglect/deprivation and abuse/trauma also are at greater risk for other negative environmental factors that may be broadly defined as abnormal or harmful input, including teratogen exposure in utero and parental psychopathology (National Research Council, 2013). Still, until broad environmental risks, such as poverty, maltreatment, and parental psychopathology are parsed into more specific components as they impact circuitry, it will be difficult to elucidate mechanisms involved in sculpting the brain. We will continue to need experimental non-human models to clearly isolate the biological outcomes resulting separately from each type of adverse experience (Maestripieri and Carroll, 1998), although ethical considerations prohibit direct testing of abusive experiences akin to those experienced by human children.

We also need more refined ways of characterizing environmental deviations. Once environmental influences can be more precisely defined, and with greater understanding of the importance of timing and sensitive periods 
in regards to the onset/offset of adverse early experiences, our ability to understand individual vulnerability, resilience, and treatment responsiveness may be enhanced. The use of laboratory-based assessments may provide the ability to capture the behavioral and neural responses to each type of input, and could provide insight into the etiology of psychopathology following both forms of deviation from the expectable environment. At the level of circuitry, a similar proposal to examine this two-pronged approach has been suggested (Sheridan and McLaughlin, 2014). Behavioral lab measures designed to approximate inadequate or harmful input (eg, the still face paradigm as a proxy for parental unresponsiveness or viewing of threatening/angry faces as a proxy for threatening parental behavior) may help identify typical reactions and individual differences to both types of input. The study of individual differences in attention bias to threat following maltreatment (Pine et al, 2005), for example, has led to increased understanding of the range of behaviors associated with anxiety, and individualized treatments to address the bias toward $v s$ bias away from threat (eg, cognitive bias modification therapy) (Hakamata et al, 2010).

The study of individual differences in response to negative input has grown markedly and continues to be a promising area for future research. Considering age, sex, and genetic differential susceptibility are important areas for further work, and could be used to help identify when and with whom prevention and treatment is likely be most effective, as well as identify pathways for greater understanding of risk mechanisms. Clearly, research studies that prospectively follow children who experienced maltreatment in early life are needed to best identify the pathways that result in psychopathology and resilience.

Negative input clearly impacts the developing brain, but so does positive input. For example, a recent study demonstrated that quality of parents' nonverbal cues to their 14- to 18-month-old children contributed to vocabulary at 54 months, even after controlling for quantity of language provided (Cartmill et al, 2013). We would do well to remember that positive environmental input likely matters with regard to influencing psychopathology, as well. In Parent Child Interaction Therapy, for example, an evidenced-based intervention for young children with emotional and behavioral disorders, parents are instructed during sessions to engage in praise, reflection, imitation, description, and enjoyment in statements to their children. This has the dual effect of interrupting typical and often maladaptive parent-child transactions, as well as introducing positive parenting behaviors (Eyberg et al, 2008). Ultimately, the goal is to tailor interventions to individuals who have specific liabilities and strengths in order to change developmental trajectories.

\section{CONCLUSIONS}

Deviations from the expectable environment have profound effects on risk for subsequent psychopathology. At the level of neural circuitry, both inadequate input and harmful input can lead to abnormal brain development and functioning. To date, the evidence regarding the association for increased risk for specific domains of psychopathology ranges from strong to uncertain depending on the type of input (eg, inadequate $v s$ harmful), and the level of potential mechanisms outlined by extant research varies. Overall, at the behavioral level, neglect/deprivation and abuse/trauma have been implicated as risk factors for serious psychopathology, even in the first years of life. Yet, considerable work remains in elucidating the neurobiological pathways by which early adverse experiences result in increased risk for negative psychopathological outcomes. In addition to the type of adverse experience, chronicity of the abuse or neglect also has an important role in outcomes, with a dose-response effect often observed in negative outcomes (Jonson-Reid et al, 2012). Contemporary research is beginning to explore brain structure and function associated with various psychopathological profiles, but a gap remains between identifying descriptive accounts of aberrant behaviors and types of symptoms and an understanding of the mechanisms by which experiences in differing environmental conditions lead to different patterns of function. We hope that this two-pronged approach considering the differential impact of inadequate $v s$ harmful input is a useful framework for understanding the potential etiological pathways from early-life adversity on the developing brain and psychopathology.

\section{FUNDING AND DISCLOSURE}

Dr Humphreys's work has been funded by the NSF and CHADD. Dr Zeanah's work has been funded by the NIH, NIEHS, and SAMSHA. He receives royalties from Guilford Press and Harvard University Press.

\section{ACKNOWLEDGEMENTS}

We thank Robert Caughey, Richelle Long, and the anonymous reviewers, for their comments on an earlier draft of this article.

\section{REFERENCES}

Achenbach TM (1991). Integrative guide for the 1991 CBCL/4-18, YSR, and TRF profiles. University of Vermont.

Alizadeh H, Applequist KF, Coolidge FL (2007). Parental self-confidence, parenting styles, and corporal punishment in families of ADHD children in Iran. Child Abus Negl 31: 567-572.

American Psychiatric Association (2013). Diagnostic and Statistical Manual of Mental Disorders. 5th Edition (DSM-5). American Psychiatric Publishing.

Bakermans-Kranenburg MJ, Steele $\mathrm{H}$, Zeanah $\mathrm{CH}$, Muhamedrahimov RJ, Vorria P, Dobrova-Krol NA et al (2011). Attachment and emotional development in institutional care: characteristics and catch up. Monogr Soc Res Child Dev 76: 62-91.

Bauer PM, Hanson JL, Pierson RK, Davidson RJ, Pollak SD (2009). Cerebellar volume and cognitive functioning in children who experienced early deprivation. Biol Psychiatry 66: 1100-1106.

Baumrind D (1993). The average expectable environment is not good enough: a response to Scarr. Child Dev 64: 1299-1317. 
Becker-Blease KA, Freyd JJ (2008). A preliminary study of ADHD symptoms and correlates: do abused children differ from nonabused children? J Aggress Maltreat Trauma 17: 133-140.

Ben-Shlomo Y, Kuh D (2002). A life course approach to chronic disease epidemiology: conceptual models, empirical challenges and interdisciplinary perspectives. Int J Epidemiol 31: 285-293.

Boden JM, Fergusson DM, Horwood LJ (2010). Risk factors for conduct disorder and oppositional/defiant disorder: evidence from a New Zealand birth cohort. J Am Acad Child Adolesc Psychiatry 49: 1125-1133.

Boggs SR, Eyberg SM, Edwards DL, Rayfield A, Jacobs J, Bagner D et al (2005). Outcomes of parent-child interaction therapy: a comparison of treatment completers and study dropouts one to three years later. Child Fam Behav Ther 26: 1-22.

Bolger KE, Patterson CJ (2001). Pathways from child maltreatment to internalizing problems: perceptions of control as mediators and moderators. Dev Psychopathol 13: 913-940.

Bomyea J, Risbrough V, Lang AJ (2012). A consideration of select pre-trauma factors as key vulnerabilities in PTSD. Clin Psychol Rev 32: 630-641.

Boris NW, Hinshaw-Fuselier SS, Smyke AT, Scheeringa MS, Heller SS, Zeanah CH (2004). Comparing criteria for attachment disorders: establishing reliability and validity in high-risk samples. J Am Acad Child Adolesc Psychiatry 43: 568-577.

Bos KJ, Fox N, Zeanah CH, Nelson CA (2009). Effects of early psychosocial deprivation on the development of memory and executive function. Front Behav Neurosci 3: 16.

Bowlby J (2008). A Secure Base: Parent-Child Attachment and Healthy Human Development. Basic Books.

Boyce WT, Ellis BJ (2005). Biological sensitivity to context: I. An evolutionarydevelopmental theory of the origins and functions of stress reactivity. Dev Psychopathol 17: 271-301.

Brett ZH, Humphreys KL, Fleming AS, Kraemer GW, Drury SS. (in press-a). Using cross species comparisons and a neurobiological framework to understand early social deprivation effects on behavioral development. Dev Psychopathol.

Brett ZH, Humphreys KL, Smyke AT, Gleason MM, Nelson CA, Zeanah CH et al (in press-b). 5HTTLPR genotype moderates the longitudinal impact of early caregiving on externalizing behavior. Dev Psychopathol.

Briscoe-Smith AM, Hinshaw SP (2006). Linkages between child abuse and attention-deficit/hyperactivity disorder in girls: behavioral and social correlates. Child Abus Negl 30: 1239-1255.

Bruce J, Tarullo AR, Gunnar MR (2009). Disinhibited social behavior among internationally adopted children. Dev Psychopathol 21: 157-171.

Carlson EA, Jacobvitz D, Sroufe LA (1995). A developmental investigation of inattentiveness and hyperactivity. Child Dev 66: 37-54.

Carlson M, Earls F (1997). Psychological and neuroendocrinological sequelae of early social deprivation in institutionalized children in Romania. Ann N Y Acad Sci 807: 419-428.

Carrion VG, Weems CF, Eliez S, Patwardhan A, Brown W, Ray RD et al (2001). Attenuation of frontal asymmetry in pediatric posttraumatic stress disorder. Biol Psychiatry 50: 943-951.

Cartmill EA, Armstrong BF, Gleitman LR, Goldin-Meadow S, Medina TN, Trueswell JC (2013). Quality of early parent input predicts child vocabulary 3 years later. Proc Natl Acad Sci USA 110: 11278-11283.

Chisholm K (1998). A three year follow-up of attachment and indiscriminate friendliness in children adopted from Romanian orphanages. Child Dev 69: 1092-1106.

Chugani HT, Behen ME, Muzik O, Juhász C, Nagy F, Chugani DC (2001). Local brain functional activity following early deprivation: a study of postinstitutionalized Romanian orphans. Neuroimage 14: 1290-1301.

Cicchetti D, Rogosch FA (2001). The impact of child maltreatment and psychopathology on neuroendocrine functioning. Dev Psychopathol 13: 783-804.

Cicchetti D, Rogosch FA (2010). The differential impacts of early physical and sexual abuse and internalizing problems on daytime cortisol rhythm in school-aged children. Child Dev 81: 252-269.

Conway F, Oster M, Szymanski K (2011). ADHD and complex trauma: a descriptive study of hospitalized children in an urban psychiatric hospital. J Infant, Child, Adolesc Psychother 10: 60-72.

Curtis WJ, Lindeke LL, Georgieff MK, Nelson CA (2002). Neurobehavioural functioning in neonatal intensive care unit graduates in late childhood and early adolescence. Brain 125: 1646-1659.

Cutajar MC, Mullen PE, Ogloff JRP, Thomas SD, Wells DL, Spataro J (2010). Psychopathology in a large cohort of sexually abused children followed up to 43 years. Child Abus Negl 34: 813-822.

Dalgleish T, Moradi AR, Taghavi MR, Neshat-Doost HT, Yule W (2001). An experimental investigation of hypervigilance for threat in children and adolescents with post-traumatic stress disorder. Psychol Med 31: 541-547.
De Bellis MD (2001). Developmental traumatology: the psychobiological development of maltreated children and its implications for research, treatment, and policy. Dev Psychopathol 13: 539-564.

De Bellis MD, Baum AS, Birmaher B, Keshavan MS, Eccard CH, Boring AM et al (1999). Developmental traumatology part I: biological stress systems. Biol Psychiatry 45: 1259-1270.

De Bellis MD, Hall J, Boring AM, Frustaci K, Moritz G (2001). A pilot longitudinal study of hippocampal volumes in pediatric maltreatment-related posttraumatic stress disorder. Biol Psychiatry 50: 305-309.

De Bellis MD, Keshavan MS, Shifflett H, lyengar S, Beers SR, Hall J et al (2002). Brain structures in pediatric maltreatment-related posttraumatic stress disorder: a sociodemographically matched study. Biol Psychiatry 52: 1066-1078.

De Bellis MD, Zisk A (2014). The biological effects of childhood trauma. Child Adolesc Psychiatr Clin N Am 23: 185-222.

Dodge KA, Pettit GS, Bates JE, Valente E (1995). Social information-processing patterns partially mediate the effect of early physical abuse on later conduct problems. J Abnorm Psychol 104: 632-643.

D'Onofrio BM, Van Hulle CA, Waldman ID, Rodgers JL, Rathouz PJ, Lahey BB (2007). Causal inferences regarding prenatal alcohol exposure and childhood externalizing problems. Arch Gen Psychiatry 64: 1296-1304.

Dong M, Anda R, Felitti V (2004). The interrelatedness of multiple forms of childhood abuse, neglect, and household dysfunction. Child Abuse Negl 28: 771-784.

Dozier M, Manni M, Gordon MK, Peloso E, Gunnar MR, Stovall-McClough KC et al (2006). Foster children's diurnal production of cortisol: an exploratory study. Child Maltreat 11: 189-197.

Drury SS, Gleason MM, Theall KP, Smyke AT, Nelson CA, Fox NA et al (2012a). Genetic sensitivity to the caregiving context: the influence of 5 httlpr and BDNF val66met on indiscriminate social behavior. Physiol Behav 106: 728-735.

Drury SS, Theall K, Gleason M, Smyke AT, De Vivo I, Wong J et al (2012b). Telomere length and early severe social deprivation: linking early adversity and cellular aging. Mol Psychiatry 17: 719-727.

Drury SS, Theall KP, Smyke AT, Keats BJB, Egger HL, Nelson CA et al (2010). Modification of depression by COMT val158met polymorphism in children exposed to early severe psychosocial deprivation. Child Abus Neg/ 34: 387-395.

Durston S, Thomas KM, Yang Y, Ulu AM, Zimmerman RD, Casey BJ (2002). A neural basis for the development of inhibitory control. Dev Sci 5: F9-F16.

Egger HL, Erkanli A, Keeler G, Potts E, Walter BK, Angold A (2006). Test-retest reliability of the preschool age psychiatric assessment (PAPA). J Am Acad Child Adolesc Psychiatry 45: 538-549.

Ellis $\mathrm{BH}$, Fisher PA, Zaharie S (2004). Predictors of disruptive behavior, developmental delays, anxiety, and affective symptomatology among institutionally reared Romanian children. J Am Acad Child Adolesc Psychiatry 43: 1283-1292.

Eluvathingal TJ, Chugani HT, Behen ME, Juhász C, Muzik O, Maqbool M et al (2006). Abnormal brain connectivity in children after early severe socioemotional deprivation: a diffusion tensor imaging study. Pediatrics 117: 2093-2100.

Eyberg SM, Nelson MM, Boggs SR (2008). Evidence-based psychosocial treatments for children and adolescents with disruptive behavior. J Clin Child Adolesc Psychol 37: 215-237.

Fairchild G, Passamonti L, Hurford G, Hagan CC, von dem Hagen EAH, van Goozen SHM et al (2011). Brain structure abnormalities in early-onset and adolescent-onset conduct disorder. Am J Psychiatry 168: 624-633.

Fantuzzo JW, delGaudio Weiss A, Atkins M, Meyers R, Noone M (1998). A contextually relevant assessment of the impact of child maltreatment on the social competencies of low-income urban children. J Am Acad Child Adolesc Psychiatry 37: 1201-1208.

Fergusson DM, Boden JM, Horwood LJ (2008). Exposure to childhood sexual and physical abuse and adjustment in early adulthood. Child Abus Neg/ 32: 607-619.

Field T (1994). The effects of mother's physical and emotional unavailability on emotion regulation. Monogr Soc Res Child Dev 59: 208-227.

Ford JD, Racusin R, Ellis CG, Daviss WB, Reiser J, Fleischer A et al (2000). Child maltreatment, other trauma exposure, and posttraumatic symptomatology among children with oppositional defiant and attention deficit hyperactivity disorders. Child Maltreat 5: 205-217.

Ford JD, Stockton P, Kaltman S, Green BL (2006). Disorders of extreme stress (DESNOS) symptoms are associated with type and severity of interpersonal trauma exposure in a sample of healthy young women. J Interpers Violence 21: 1399-1416.

Frick PJ, Nigg JT (2012). Current issues in the diagnosis of attention deficit hyperactivity disorder, oppositional defiant disorder, and conduct disorder. Annu Rev Clin Psychol 8: 77-107.

Fox SE, Levitt P, Nelson CA (2010). How the timing and quality of early experiences influence the development of brain architecture. Child Dev 81: 28-40.

Gee DG, Gabard-Durnam LJ, Flannery J, Goff B, Humphreys KL, Telzer EH et al (2013). Early developmental emergence of human amygdala-prefrontal connectivity after maternal deprivation. Proc Natl Acad Sci USA 110: 15638-15643. 
Ghera MM, Marshall PJ, Fox N a, Zeanah CH, Nelson C a, Smyke AT et al (2009). The effects of foster care intervention on socially deprived institutionalized children's attention and positive affect: results from the BEIP study. J Child Psychol Psychiatry 50: 246-253.

Gleason MM, Fox NA, Drury S, Smyke A, Egger HL, Nelson CA et al (2011a). Validity of evidence-derived criteria for reactive attachment disorder: indiscriminately social/disinhibited and emotionally withdrawn/inhibited types. J Am Acad Child Adolesc Psychiatry 50: 216-231.

Gleason MM, Zamfirescu A, Egger HL, Nelson CA, Fox NA, Zeanah CH (2011b). Epidemiology of psychiatric disorders in very young children in a Romanian pediatric setting. Eur Child Adolesc Psychiatry 20: 527-535.

Goldfarb W (1945). Psychological privation in infancy and subsequent adjustment. Am J Orthopsychiatry 15: 247-255.

Govindan RM, Behen ME, Helder E, Makki MI, Chugani HT (2010). Altered water diffusivity in cortical association tracts in children with early deprivation identified with Tract-Based Spatial Statistics (TBSS). Cereb Cortex 20: 561-569.

Greenough WT, Black JE, Wallace CS (1987). Experience and brain development. Child Dev 58: 539-559.

Gunnar MR, Bruce J, Grotevant HD (2000). International adoption of institutionally reared children: research and policy. Dev Psychopathol 12: 677-693.

Gunnar MR, Morison SJ, Chisholm K, Schuder M (2001). Salivary cortisol levels in children adopted from romanian orphanages. Dev Psychopathol 13: 611-628.

Gunnar MR, van Dulmen M. International Adoption Project Team (2007). Behavior problems in post-institutionalized internationally adopted children. Dev Psychopathol 19: 129-148.

Hakamata Y, Lissek S, Bar-Haim Y, Britton JC, Fox NA, Leibenluft E et al (2010). Attention bias modification treatment: a meta-analysis toward the establishment of novel treatment for anxiety. Biol Psychiatry 68: 982-990.

Halfon N, Hochstein M (2002). Life course health development: an integrated framework for developing health, policy, and research. Milbank Q 80: 433-479.

Hart B, Risley TR (1995). Meaningful Differences in the Everyday Experience of Young American Children. Brookes: Baltimore, MD.

Heneghan A, Stein REK, Hurlburt MS, Zhang J, Rolls-Reutz J, Fisher E et al (2013). Mental health problems in teens investigated by U.S. child welfare agencies. J Adolesc Heal 52: 634-640.

Hertzman C, Wiens M (1996). Child development and long-term outcomes: a population health perspective and summary of successful interventions. Soc Sci Med 43: 1083-1095.

Humphreys KL, Zeanah $\mathrm{CH}$, Scheeringa MS. (in press). Infant development. The first 3 years of life. In: Tasman A, Kay J, Lieberman JA, First MB, Riba M (eds). Psychiatry. 4th edn, Wiley-Blackwell.

Hunt JM (1979). Psychological development: early experience. Annu Rev Psychol 30: 103-144

Jackowski AP, Douglas-Palumberi H, Jackowski M, Win L, Schultz RT, Staib LW et al (2008). Corpus callosum in maltreated children with PTSD: a diffusion tensor imaging study. Psychiatry Res 162: 256-261.

Johnson DE, Guthrie D, Smyke AT, Koga SF, Fox NA, Zeanah CH et al (2010). Growth and associations between auxology, caregiving environment, and cognition in socially deprived Romanian children randomized to foster vs ongoing institutional care. Arch Pediatr Adolesc Med 164: 507-516.

Jones AP, Laurens KR, Herba CM, Barker GJ, Viding E (2009). Amygdala hypoactivity to fearful faces in boys with conduct problems and callousunemotional traits. Am J Psychiatry 166: 95-102.

Jones W, Bellugi U, Lai Z, Chiles M, Reilly J, Lincoln A et al (2000). Hypersociability in Williams syndrome. J Cogn Neurosci 12: 30-46.

Jonson-Reid M, Kohl PL, Drake B (2012). Child and adult outcomes of chronic child maltreatment. Pediatrics 129: 839-845.

Kaplow JB, Widom CS (2007). Age of onset of child maltreatment predicts longterm mental health outcomes. J Abnorm Psychol 116: 176-187.

Kearney CA, Wechsler A, Kaur H, Lemos-Miller A (2010). Posttraumatic stress disorder in maltreated youth: a review of contemporary research and thought. Clin Child Fam Psychol Rev 13: 46-76.

Keiley MK, Howe TR, Dodge KA, Bates JE, Petti GS (2001). The timing of child physical maltreatment: a cross-domain growth analysis of impact on adolescent externalizing and internalizing problems. Dev Psychopathol 13: 891-912.

Kessler RC, Sonnega A, Bromet E, Hughes M, Nelson CB (1995). Posttraumatic stress disorder in the National Comorbidity Survey. Arch Gen Psychiatry 52: 1048-1060.

Kim J, Cicchetti D (2010). Longitudinal pathways linking child maltreatment, emotion regulation, peer relations, and psychopathology. J Child Psychol Psychiatry 51: 706-716.

Kim-Cohen J, Caspi A, Taylor A, Williams B, Newcombe R, Craig IW et al (2006). MAOA, maltreatment, and gene-environment interaction predicting children's mental health: new evidence and a meta-analysis. Mol Psychiatry 11: 903-913.
Knudsen El (2004). Sensitive periods in the development of the brain and behavior J Cogn Neurosci 16: 1412-1425.

Kolko DJ, Hurlburt MS, Zhang J, Barth RP, Leslie LK, Burns BJ (2010). Posttraumatic stress symptoms in children and adolescents referred for child welfare investigation. A national sample of in-home and out-of-home care. Child Maltreat 15: 48-63.

Kotch JB, Lewis T, Hussey JM, English D, Thompson R, Litrownik AJ et al (2008). Importance of early neglect for childhood aggression. Pediatrics 121: 725-731

Kreppner JM, O'Connor TG, Rutter M (2001). Can inattention/overactivity be an institutional deprivation syndrome? J Abnorm Child Psychol 29: 513-528.

Kreppner JM, Rutter M, Beckett C, Castle J, Colvert E, Groothues C et al (2007). Normality and impairment following profound early institutional deprivation: a longitudinal follow-up into early adolescence. Dev Psychol 43: 931-946.

Lansford JE, Dodge K, Pettit GS, Bates JE, Crozier J, Kaplow J (2002). A 12-year prospective study of the long-term effects of early child physical maltreatment on psychological, behavioral, and academic problems in adolescence. Arch Pediatr Adolesc Med 156: 824-830.

Lawler JM, Hostinar CE, Miliner SB, Gunnar MR (2014). Disinhibited social engagement in postinstitutionalized children: differentiating normal from atypical behavior. Dev Psychopathol 26: 451-461.

Lerner RM, Overton WF (2008). Exemplifying the integrations of the relational developmental system: synthesizing theory, research, and application to promote positive development and social justice. J Adolesc Res 23: 245-255.

Levy F, Hay DA, McStephen M, Wood C, Waldman I (1997). Attention-deficit hyperactivity disorder: a category or a continuum? Genetic analysis of a largescale twin study. J Am Acad Child Adolesc Psychiatry 36: 737-744.

Lewis EE, Dozier M, Ackerman J, Sepulveda-Kozakowski S (2007). The effect of placement instability on adopted children's inhibitory control abilities and oppositional behavior. Dev Psychol 43: 1415-1427.

Li JJ, Lee SS (2012). Interaction of dopamine transporter (DAT1) genotype and maltreatment for ADHD: a latent class analysis. J Child Psychol Psychiatry 53: 997-1005.

Lifford KJ, Harold GT, Thapar A (2008). Parent-child relationships and ADHD symptoms: a longitudinal analysis. J Abnorm Child Psychol 36: 285-296.

Loman MM, Johnson AE, Westerlund A, Pollak SD, Nelson CA, Gunnar MR (2013). The effect of early deprivation on executive attention in middle childhood. J Child Psychol Psychiatry 54: 37-45.

Lupien SJ, McEwen BS, Gunnar MR, Heim C (2009). Effects of stress throughout the lifespan on the brain, behaviour and cognition. Nat Rev Neurosci 10 434-445

Lyons-Ruth K, Bureau JF, Riley CD, Atlas-Corbett AF (2009). Socially indiscriminate attachment behavior in the strange situation: convergent and discriminant validity in relation to caregiving risk, later behavior problems, and attachment insecurity. Dev Psychopathol 21: 355-372.

Maestripieri D, Carroll KA (1998). Child abuse and neglect: usefulness of the animal data. Psychol Bull 123: 211-223.

Manly JT, Kim JE, Rogosch FA, Cicchetti D (2001). Dimensions of child maltreatment and children's adjustment: contributions of developmental timing and subtype. Dev Psychopathol 13: 759-782.

Marcus DK, Barry TD (2011). Does attention-deficit/hyperactivity disorder have a dimensional latent structure? A taxometric analysis. J Abnorm Psychol 120: 427-442

Marshall PJ, Fox NA, BEIP Core Group (2004). A comparison of the electroencephalogram between institutionalized and community children in Romania. J Cogn Neurosci 16: 1327-1338.

Marshall PJ, Reeb BC, Fox NA, Nelson CA, Zeanah CH (2008). Effects of early intervention on EEG power and coherence in previously institutionalized children in Romania. Dev Psychopathol 20: 861-880.

McCrory EJ, De Brito SA, Sebastian CL, Mechelli A, Bird G, Kelly PA et al (2011). Heightened neural reactivity to threat in child victims of family violence. Curr Bio 21: R947-R948.

McEwen BS (1998). Stress, adaptation, and disease. Allostasis and allostatic load. Ann N Y Acad Sci 840: 33-44.

McEwen BS, Seeman T (1999). Protective and damaging effects of mediators of stress. Elaborating and testing the concepts of allostasis and allostatic load. Ann N Y Acad Sci 896: 30-47.

McGoron L, Zeanah CH, Frick PJ, Nelson CA, Fox NA (2013). Callous-unemotional traits in children with a history of institutional care. Fifth Biennial Meeting for Scientific Study of Psychopathy.

McLaughlin KA, Fox NA, Zeanah CH, Sheridan MA, Marshall P, Nelson CA (2010). Delayed maturation in brain electrical activity partially explains the association between early environmental deprivation and symptoms of attention-deficit/ hyperactivity disorder. Biol Psychiatry 68: 329-336. 
McLaughlin KA, Sheridan MA, Lambert HK (2014). Childhood adversity and neural development: deprivation and threat as distinct dimensions of early experience. Manuscript under Editorial Review.

McLaughlin KA, Sheridan MA, Winter W, Fox NA, Zeanah CH, Nelson CA (2013). Widespread reductions in cortical thickness following severe early-life deprivation: a neurodevelopmental pathway to attention-deficit/hyperactivity disorder. Biol Psychiatry print copy in press (originally published online 30 September 2013, at http://www.biologicalpsychiatryjournal.com/article/S00063223(13)00769-5/)

Mehta MA, Golembo NI, Nosarti C, Colvert E, Mota A, Williams SCR et al (2009). Amygdala, hippocampal and corpus callosum size following severe early institutional deprivation: the English and Romanian Adoptees study pilot. J Child Psychol Psychiatry 50: 943-951.

Mennen FE, Kim K, Sang J, Trickett PK (2010). Child neglect: definition and identification of youth's experiences in official reports of maltreatment. Child Abus Neg/ 34: 647-658.

Miller L, Chan W, Litvinova A (2006). Fetal alcohol spectrum disorders in children residing in Russian orphanages: a phenotypic survey. Alcohol Clin Exp Res 30: 531-538.

Murray-Close D, Han G, Cicchetti D, Crick NR, Rogosch FA (2008). Neuroendocrine regulation and physical and relational aggression: the moderating roles of child maltreatment and gender. Dev Psychol 44: 1160-1176.

Narr KL, Woods RP, Lin J, Kim J, Phillips OR, Del'Homme M et al (2009). Widespread cortical thinning is a robust anatomical marker for attentiondeficit/hyperactivity disorder. J Am Acad Child Adolesc Psychiatry 48: 1014-1022.

National Research Council (2013). New Directions in Child Abuse and Neglect Research. National Academies Press.

Nelson CA, Bos K, Gunnar MR, Sonuga-Barke EJ (2011). The neurobiological toll of early human deprivation. Monogr Soc Res Child Dev 76: 127-146.

Nelson CA, Fox NA, Zeanah CH (2014). Romania's Abandoned Children. Harvard University Press

Neubauer S, Hublin J-J (2012). The evolution of human brain development. Evol Biol 39: 568-586.

O'Connor TG, Marvin RS, Rutter M, Olrick JT, Britner PA (2003). Childparent attachment following early institutional deprivation. Dev Psychopathol 15: 19-38.

Olsavsky AK, Telzer EH, Shapiro M, Humphreys KL, Flannery J, Goff B et al (2013). Indiscriminate amygdala response to mothers and strangers after early maternal deprivation. Biol Psychiatry 74: 853-860.

Oosterman M, Schuengel C, Wim Slot N, Bullens RAR, Doreleijers TAH (2007). Disruptions in foster care: a review and meta-analysis. Child Youth Serv Rev 29: 53-76

Ouyang L, Fang X. Mercy J, Perou R, Grosse SD (2008). Attention-deficit/ hyperactivity disorder symptoms and child maltreatment: a population-based study. J Pediatr 153: 851-856.

Passamonti L, Fairchild G, Fornito A, Goodyer IM, Nimmo-Smith I, Hagan CC et al (2012). Abnormal anatomical connectivity between the amygdala and orbitofrontal cortex in conduct disorder. PLoS One 7: e48789.

Patterson GR (2002). The early development of coercive family process. In: Reid JB, Patterson GR, Snyder J (eds). Antisocial Behavior in Children and Adolescents: Developmental Theories and Models for Intervention. American Psychological Association: Washington, DC, pp 25-44.

Pears KC, Bruce J, Fisher PA, Kim HK (2010). Indiscriminate friendliness in maltreated foster children. Child Maltreat 15: 64-75.

Pine DS, Mogg K, Bradley BP, Montgomery L, Monk CS, McClure E et al (2005). Attention bias to threat in maltreated children: implications for vulnerability to stress-related psychopathology. Am J Psychiatry 162: 291-296.

Polanczyk G, de Lima MS, Horta BL, Biederman J, Rohde LA (2007). The worldwide prevalence of ADHD: a systematic review and metaregression analysis. Am J Psychiatry 164: 942-948.

Pollak SD, Cicchetti D, Klorman R, Brumaghim JT (1997). Cognitive brain eventrelated potentials and emotion processing in maltreated children. Child Dev 68: 773-787.

Pollak SD, Klorman R, Thatcher JE, Cicchetti D (2001). P3b reflects maltreated children's reactions to facial displays of emotion. Psychophysiology 38: 267-274.

Pollak SD, Sinha P (2002). Effects of early experience on children's recognition of facial displays of emotion. Dev Psychol 38: 784-791.

Pollak SD, Tolley-Schell SA (2003). Selective attention to facial emotion in physically abused children. J Abnorm Psychol 112: 323-338.

Richert KA, Carrion VG, Karchemskiy A, Reiss AL (2006). Regional differences of the prefrontal cortex in pediatric PTSD: an MRI study. Depress Anxiety 25: $17-25$.

Romens SE, Svaren J, Pollak SD. (in press). Associations between early life stress and gene methylation in children. Child Dev.
Roy P, Rutter M, Pickles A (2004). Institutional care: associations between overactivity and lack of selectivity in social relationships. J Child Psychol Psychiatry 45: 866-873.

Rutter M, Kreppner J, Sonuga-Barke E (2009). Emanuel Miller lecture: attachment insecurity, disinhibited attachment, and attachment disorders: where do research findings leave the concepts? J Child Psychol Psychiatry 50: 529-543.

Rutter M, Sonuga-Barke EJ, Beckett C, Bell CA, Kreppner J, Kumsta R et al (2010a). Deprivation-specific psychological patterns: effects of institutional deprivation by the English and Romanian Adoptee Study Team. Monogr Soc Res Child Dev 75: 1-252.

Rutter M, Sonuga-Barke EJ, Castle J (2010b). I. Investigating the impact of early institutional deprivation on development: background and research strategy of the English and Romanian Adoptees (ERA) study. Monogr Soc Res Child Dev 75: $1-20$.

Sameroff AJ, Chandler MJ (1975). Reproductive risk and the continuum of caretaking casualty. Rev Child Dev Res 4: 187-244.

Scarr S (1992). Developmental theories for the 1990s: development and individual differences. Child Dev 63: 1-19.

Scheeringa MS, Wright MJ, Hunt JP, Zeanah CH (2006). Factors affecting the diagnosis and prediction of PTSD symptomatology in children and adolescents. Am J Psychiatry 163: 644-651.

Scheeringa MS, Zeanah CH (1995). Symptom expression and trauma variables in children under 48 months of age. Infant Ment Health J 16: 259-270.

Scheeringa MS, Zeanah CH, Cohen JA (2011). PTSD in children and adolescents: toward an empirically based algorithma. Depress Anxiety 28: 770-782

Scheeringa MS, Zeanah CH, Myers L, Putnam FW (2003). New findings on alternative criteria for PTSD in preschool children. J Am Acad Child Adolesc Psychiatry 42: 561-570.

Shackman JE, Shackman AJ, Pollak SD (2007). Physical abuse amplifies attention to threat and increases anxiety in children. Emotion 7: 838-852.

Shalev I, Moffitt TE, Sugden K, Williams B, Houts RM, Danese A et al (2012). Exposure to violence during childhood is associated with telomere erosion from 5 to 10 years of age: a longitudinal study. Mol Psychiatry 18: 576-581.

Shaw DS, Hyde LW, Brennan LM (2012). Early predictors of boys' antisocial trajectories. Dev Psychopathol 24: 871-888.

Shaw P, Lerch J, Greenstein D, Sharp W, Clasen L, Evans A et al (2006). Longitudinal mapping of cortical thickness and clinical outcome in children and adolescents with attention-deficit/hyperactivity disorder. Arch Gen Psychiatry 63: 540-549.

Sheridan MA, Fox NA, Zeanah CH, McLaughlin KA, Nelson CA (2012). Variation in neural development as a result of exposure to institutionalization early in childhood. Proc Natl Acad Sci USA 109: 12927-12932.

Sheridan MA, McLaughlin KA (2014). Dimensions of early experience and neural development: deprivation and threat. Manuscript under Editorial Review.

Shields A, Cicchetti D (2001). Parental maltreatment and emotion dysregulation as risk factors for bullying and victimization in middle childhood. J Clin Child Psychol 30: 349-363.

Shonkoff JP, Garner AS (2012). The lifelong effects of early childhood adversity and toxic stress. Pediatrics 129: e232-e246.

Singer MJ, Humphreys KL, Lee SS (2012). Coping self-efficacy mediates the association between child abuse and ADHD in adulthood. J Atten Disord print copy in press (originally published online 29 November 2012, at http:// jad.sagepub.com/content/early/2012/11/29/1087054712465337/).

Slopen N, McLaughlin KA, Fox NA, Zeanah CH, Nelson CA (2012). Alterations in neural processing and psychopathology in children raised in institutions. Arch Gen Psychiatry 69: 1022-1030.

Smith DK, Johnson AB, Pears KC, Fisher PA, DeGarmo DS (2007). Child maltreatment and foster care: unpacking the effects of prenatal and postnatal parental substance use. Child Maltreat 12: 150-160.

Smyke AT, Dumitrescu A, Zeanah CH (2002). Attachment disturbances in young children. I: the continuum of caretaking casualty. J Am Acad Child Adolesc Psychiatry 41: 972-982.

Smyke AT, Koga SF, Johnson DE, Fox NA, Marshall PJ, Nelson CA et al (2007). The caregiving context in institution-reared and family-reared infants and toddlers in Romania. J Child Psychol Psychiatry 48: 210-218.

Snyder SM, Hall JR (2006). A meta-analysis of quantitative EEG power associated with attention-deficit hyperactivity disorder. J Clin Neurophysiol 23: 440-455.

Soares I, Belsky J, Mesquita AR, Osorio A, Sampaio A (2013). Why do only some institutionalized children become indiscriminately friendly? Insights from the study of Williams Syndrome. Child Dev Perspect 7: 187-192.

Sonuga-Barke EJS, Beckett C, Kreppner J, Castle J, Colvert E, Stevens S et al (2008). Is sub-nutrition necessary for a poor outcome following early institutional deprivation? Dev Med Child Neurol 50: 664-671. 
Spitz RA (1945). Hospitalism; an inquiry into the genesis of psychiatric conditions in early childhood. Psychoanal Study Child 1: 53-74.

Sroufe LA (1983). Infant-caregiver attachment and patterns of adaptation in preschool: the roots of maladaptation and competence. Dev Policy Concern Child with Spec Needs (Minnesota Symp Child Psychol 16: 41-83.

Stevens SE, Sonuga-Barke EJS, Kreppner JM, Beckett C, Castle J, Colvert E et al (2008). Inattention/overactivity following early severe institutional deprivation: presentation and associations in early adolescence. J Abnorm Child Psychol 36: 385-398.

Stouthamer-Loeber M, Loeber R, Homish DL, Wei E (2001). Maltreatment of boys and the development of disruptive and delinquent behavior. Dev Psychopathol 13: $941-955$.

Suliman S, Mkabile SG, Fincham DS, Ahmed R, Stein DJ, Seedat S (2009). Cumulative effect of multiple trauma on symptoms of posttraumatic stress disorder, anxiety, and depression in adolescents. Compr Psychiatry 50: $121-127$.

Tarullo AR, Garvin MC, Gunnar MR (2011). Atypical EEG power correlates with indiscriminately friendly behavior in internationally adopted children. Dev Psychol 47: 417-431.

Thornberry TP, Ireland TO, Smith CA (2001). The importance of timing: the varying impact of childhood and adolescent maltreatment on multiple problem outcomes. Dev Psychopathol 13: 957-979.

Tibu F, Humphreys KL, Fox NA, Nelson CA, Zeanah CA (2014). Psychopathology in young children in two types of foster care following institutional rearing. Infant Ment Health J 35: 123-131.

Tottenham N, Hare TA, Quinn BT, McCarry TW, Nurse M, Gilhooly T et al (2010). Prolonged institutional rearing is associated with atypically large amygdala volume and difficulties in emotion regulation. Dev Sci 13: 46-61.

Trickey D, Siddaway AP, Meiser-Stedman R, Serpell L, Field AP (2012). A metaanalysis of risk factors for post-traumatic stress disorder in children and adolescents. Clin Psychol Rev 32: 122-138.

Tronick EZ (1989). Emotions and emotional communication in infants. Am Psychol 44: 112-119.

van der Kolk BA (2003). Psychological Trauma. American Psychiatric Press.

van der Kolk BA (2005). Developmental trauma disorder. Psychiatr Ann 35: 401-408.

Vanderwert RE, Marshall PJ, Nelson CA, Zeanah CH, Fox NA (2010). Timing of intervention affects brain electrical activity in children exposed to severe psychosocial neglect. PLoS One 5: e11415.

Viding E, Frick PJ, Plomin R (2007). Aetiology of the relationship between callousunemotional traits and conduct problems in childhood. $\mathrm{Br} J$ Psychiatry 49: s33-s38.

Webb E (2013). Poverty, maltreatment and attention deficit hyperactivity disorder. Arch Dis Child 98: 397-400.
White MG, Bogdan R, Fisher PM, Muñoz KE, Williamson DE, Hariri AR (2012). FKBP5 and emotional neglect interact to predict individual differences in amygdala reactivity. Genes Brain Behav 11: 869-878.

Widom CS (1998). Childhood victimization: early adversity and subsequent psychopathology. In: Dohrenwend BP (ed). Adversity, Stress, and Psychopathology. Oxford University Press, pp 81-95.

Widom CS (1999). Posttraumatic stress disorder in abused and neglected children grown up. Am J Psychiatry 156: 1223-1229.

Wiik KL, Loman MM, Van Ryzin MJ, Armstrong JM, Essex MJ, Pollak SD et al (2011). Behavioral and emotional symptoms of post-institutionalized children in middle childhood. J Child Psychol Psychiatry 52: 56-63.

Wilson KR, Hansen DJ, Li M (2011). The traumatic stress response in child maltreatment and resultant neuropsychological effects. Aggress Violent Behav 16: 87-97.

Wismer Fries AB, Shirtcliff EA, Pollak SD (2008). Neuroendocrine dysregulation following early social deprivation in children. Dev Psychobiol 50: 588-599.

Wismer Fries AB, Ziegler TE, Kurian JR, Jacoris S, Pollak SD (2005). Early experience in humans is associated with changes in neuropeptides critical for regulating social behavior. Proc Natl Acad Sci USA 102: 17237-17240.

Woon FL, Hedges DW (2008). Hippocampal and amygdala volumes in children and adults with childhood maltreatment-related posttraumatic stress disorder: a meta-analysis. Hippocampus 18: 729-736.

Wozniak J, Crawford MH, Biederman J, Faraone S V, Spencer TJ, Taylor A et al (1999). Antecedents and complications of trauma in boys with ADHD: findings from a longitudinal study. J Am Acad Child Adolesc Psychiatry 38: 48-55.

Zeanah $\mathrm{CH}$ (2014). Psychopathology at age 12 years in children who experienced institutional rearing. 14th World Congrress of the World Association for Infant Mental Health.

Zeanah CH, Egger HL, Smyke AT, Nelson CA, Fox NA, Marshall PJ et al (2009). Institutional rearing and psychiatric disorders in Romanian preschool children. Am J Psychiatry 166: 777-785.

Zeanah $\mathrm{CH}$, Gleason MM (in press). Attachment disorders in early childhood: clinical presentation, causes, correlates and treatment. J Child Psychol Psychiatry.

Zeanah CH, Nelson CA, Fox NA, Smyke AT, Marshall P, Parker SW et al (2003). Designing research to study the effects of institutionalization on brain and behavioral development: the Bucharest Early Intervention Project. Dev Psychopathol 15: 885-907.

Zeanah CH, Scheeringa M, Boris NW, Heller SS, Smyke AT, Trapani J (2004). Reactive attachment disorder in maltreated toddlers. Child Abus Negl 28: 877-888.

Zeanah CH, Smyke AT, Dumitrescu A (2002). Attachment disturbances in young children. II: indiscriminate behavior and institutional care. J Am Acad Child Adolesc Psychiatry 41: 983-989.

Zeanah CH, Smyke AT, Koga SF, Carlson E (2005). Attachment in institutionalized and community children in Romania. Child Dev 76: 1015-1028. 